Jurnal As-Salam, 2(1) Januari - April 2018
(Print ISSN 2528-1402, Online ISSN 2549-5593)

\title{
PERANAN PEMERINTAH DALAM MENGAWASI PASAR PERSPEKTIF EKONOMI ISLAM
}

\author{
Mahadir \\ STAIN Gajah Putih Takengon, Aceh Tengah, Aceh \\ Email: mhadir.aby@gmail.com
}

\begin{abstract}
Abstrak. Pasar adalah tepat bertemunya penjual dan pembeli untuk melakukan transaksi atas barang dan jasa. Pasar berperan penting dalam menggerakkan roda kehidupan ekonomi masyarakat di suatu daerah. Sejatinya pasar merupakan elemen ekonimi yang dapat mewujudkan kemaslahatan dan kesejahteraan bagi kehidupan manusia. Namun kemaslahatan ini bisa menjadi bencana dan mendatangkan permasalahan jika perdagangan yang terjadi dipasar dilakukan tanpa mengikuti aturan. Pasar dan perdagangan yang terjadi didalamnya yang tujun dasarnya adalah untuk mencari keuntungan sesuai aturan, sewaktu-waktu dapat diselewengkan oleh oknum pelaku ekonomi dengan tujuan mendapatkan keuntungan lebih. Jika diperhatikan lebih jauh pada pasar-pasar tradisional khususnya banyak ditemukan praktek penyelewengan dan kecurangan dalam mengukur, menakar atau menimbang barang. Pemandangan lainnya yang menghiasi pasar adalah tata kelola pasar yang sangat tidak rapi dan terkesan semberautan. Untuk berjualan dan mendapatkan keuntungan lebih, banyak dari para pedagang yang menggunakan trotoar jalan atau bahkan sebagian badan jalan untuk berjualan. Ada juga yang memarkirkan kendaraan roda dua dan roda empat untuk berjualan disepanjang jalan-jalan pasar yang sangat menyulitkan para pembeli dan menyebabkan kemacetan panjang. Hal ini seharusnya tidak terjadijika pemerintah menjalankan peran dan tugasnya dalam mengawasi pasar sesuai dengan aturan dan ketentuan yang ada.
\end{abstract}

Kata kunci: Pemerintah, Alhisbah, perdagangan.

\section{Pendahuluan}

Kegiatan Perdagangan memiliki peran yang sangat pnting dalam kehidupan manusia. Sektor perdagangan dianggap cukup menjanjikan dalam meningkatkan kesejahteraan kehidupan manusia. Pasar adalah salah satu tempat setrategis untuk bertemunya penjual dan pembeli guna melakukan transaksi jual beli. Pasar dan perdagangan yang terjadi didalamnya yang tujun dasarnya adalah untuk mencari keuntungan dengan cara dan aturan main yang telah ditetapkan, sewaktu-waktu dapat diselewengkan oleh oknum pelaku ekonomi dengan tujuan mendapatkan keuntungan lebih.

Di pasar-pasar tradisional banyak ditemukan pedagang yang melakukan kecurangan dalam mengukur, menakar dan menimbang barang. Kecurangan yang dilakukan baik dalam penggunaan alat-alat ayang tidak layak lagi maupun bermain dalam isi atau berat takaran. Berat barang yang seharusnya $1 \mathrm{~kg}$ terdiri dari 10 ons, ternyata setelah ditimbang kembali ternyata hanya 9 ons. Hal ini sedah menjadi pengalaman keseharian dipasar tradisional.

Disisi lain, Islam telah memberikan aturan tentang masalah takaran dan timbangan. Dalam Alquran disebutkan secara tegas perintah untuk menyempurnakan takaran dan timbangan secara benar, perintah ini juga dibarengi dengan ancaman bagi orang yang melakukan kecurangan. Terdapat perintah yang menyatakan bahwa setiap 
muslim harus menyempurnakan takaran dan timbangan secar adil dan sempurna. Hal ini ditegaskan oleh Allah dalam Alquran surat Al-An'am: 152.

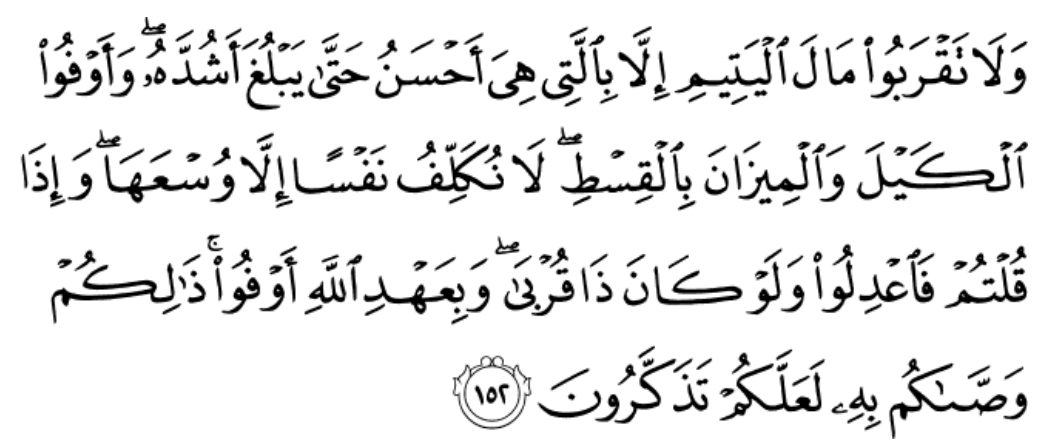

Artinya: Dan janganlah kamu dekati harta anak yatim, kecuali dengan cara yang lebih bermanfaat, hingga sampai ia dewasa. Dan sempurnakanlah takaran dan timbangan dengan adil. Kami tidak memikulkan beban kepada sesorang melainkan sekedar kesanggupannya. dan apabila kamu berkata, Maka hendaklah kamu Berlaku adil, Kendatipun ia adalah kerabatmul, dan penuhilah janji Allah ${ }^{2}$. yang demikian itu diperintahkan Allah kepadamu agar kamu ingat.

Menyempurnakan takaran dan timbangan dalam ayat ini hukumnya adalah wajib. Maka menyempurnakan takaran dan timbangan merupakan ketentuan yang wajib dipenuhi oleh setiap individu. Ketika nabi datang ke Madinah, ia mendapati penduduk madinah curang dalam takaran dan timbangan, pada saat itulah Allah menurunkan ayat yang mengancam keras pelaku kecurangan dalam takaran dan timbanagan. Ancaman ini terdapat dalam Alquran surat Al-Muthaffifin: 1-3.

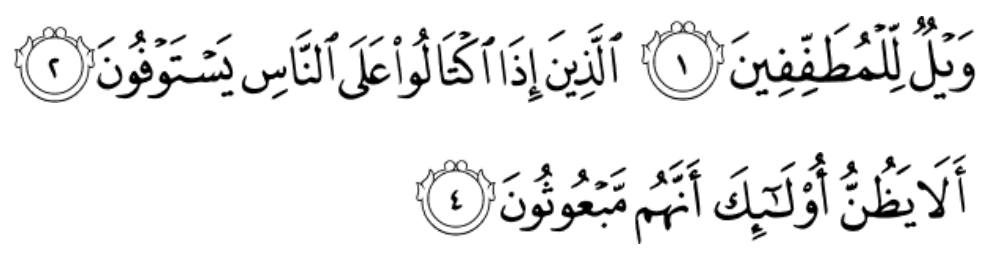

Artijnya: (1) Kecelakaan besarlah bagi orang-orang yang curang. ${ }^{3}$ (2) Yaitu orang-orang yang apabila menerima takaran dari orang lain mereka minta dipenuhi, (3) dan apabila mereka menakar atau menimbang untuk orang lain, mereka mengurangi.

Dalam ekonomi Islam, urusan takaran dan timbangan bukan hanya menjadi urusan individu seseorang atau lebih, akan tetapi menjdi urusan negara. Pemerintah mempunyai tugas dan wewenang dalam mengatur dan mengawasi pasar yang salah

\footnotetext{
${ }^{1}$ Maksudnya mengatakan yang sebenarnya meskipun merugikan Kerabat sendiri.

${ }^{2}$ Maksudnya penuhilah segala perintah-perintah-Nya.

${ }^{3}$ Yang dimaksud dengan orang-orang yang curang di sini ialah orang-orang yang curang dalam menakar dan menimbang.
} 
satunya urusan takaran dan timbangan sebagai bentuk antisipasi terjadinya kecurangan. Lembaga yang bertugas dalam pengawasan ini adalah lembaga $\mathrm{Al}$ - $\mathrm{Hisba}^{4}$

\section{Pengertian, Tugas dan Wewenang Al-hisbah}

Al-hisbah adalah masdar dari kata حسب - يحسب yang berarti menghitung atau mengira. Hisbah juga memiliki pengertian upah, balasan dan pahala yang diharpkan dari Alla SWT. Disamping itu hisbah juga berarti pengaturan yang baik. Secara terminologi Ibnu Taimiyah mendefenisikan hisbah merupakan lembaga yang mempunyai wewenang untuk menegakkan amar ma'ruf nahi munkar yang bukan termasuk wewenang umara (penguasa), qada dan wilyah almadzalim. Sedangkan Almawardi mendefenisikan hisbah sebagai lembaga yang berwenang menjalan amar ma'ruf nahi munkar. ${ }^{5}$

Ibnu Khaldun menyatakan bahwa hisbah merupakan institusi keagamaan yang termasuk bagian dari amar ma'ruf dan nahi munkar yang merupakan kewajiban bagi seluruh persoalan kaum muslimin. ${ }^{6}$ Defenisi ini sangatlah umum dan mencakup semua aspek kehidupan sosial ekonomi dan agama. Namun defenisi yang lebih spesifik dikemukakan oleh Rafiq Yunus Almisri: Hisbah adalah petugas yang bertugas mengawasi pasar serta tingkah laku masyarakat. Dalam kamus al-hadi ila lughah alarabiyah dikemukakan, bahwa al-hisbah adalah tugas yang dilakukan oleh negara untuk memastikan bahwa rakyat melakukan perintah dan menjauhi larangan syara yang berkaitan dengan takaran dan timbang yang benar dan mengawasi jalannya jual beli untuk menghilangkan tipuan dan sejenisnya.

Berdasarkan definisi ini setidaknya ada tiga poin penting terkait al-hisbah sebagai lembaga yang mewakili pemerintah dalam menjalankan tugas dan wewenangnya sebagai pengawas pasar. ${ }^{7}$ 1). Al-hisbah adalah institusi atau lembaga yang secara khusus dibentuk oleh pemerintah; 2). Tugas utama al-hisbah adalah al-amru bi al-ma'ruf dan an-nahyu 'anil al-munkar; 3). Tugas khusus al-hisbah adalah mengawasi berbagai kegiatan ekonomi dipasar, menjaga mekanisme pasar agar berjalan normal dan tidak terdistorsi serta melakukan tindakan korektif ketika terjadi distorsi pasar.

Hisbah disyariatkan dalam Islam berdasarkan isyarat yang terdapat dalam AlQur'an surat Ali-Imran ayat 104:

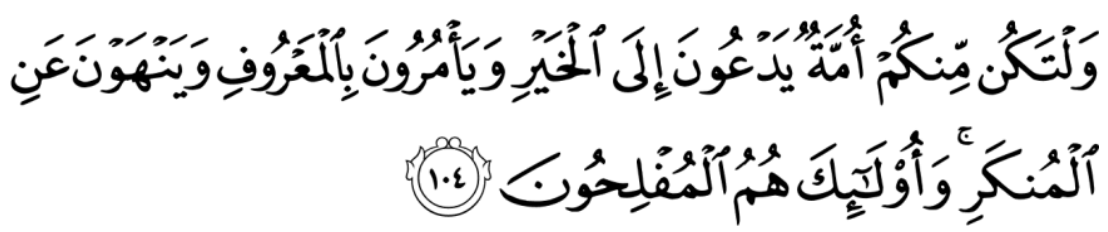

\footnotetext{
${ }^{4}$ Alhisbah adalah petugas yang berwenang mengawasi pasar serta tingkah laku masyarakat. Dalam bahasa lain Al-Hisbah adalah tugas yang dilakukan oleh negara untuk memastikan bahwa rakyat melakukan perintah dan menjauhi larangan syara berkaitan dengan takaran dan timbangan yang benar serta mengawasi jalannya jual beli untuk menghilangkan tipuan dan sejensnya. Petugas Al-Hisbah dinamakan dengan Muhtasib atau Shahib al-Suq (Pengawas Pasar).

5 Abdul Azim Islahi, Ekonomi Consepts Of Ibnu Taimiyah, (London : The Islamic Foundation, 1824), h.187.

${ }^{6}$ Abdurrahman Ibnu Khaldun, Muqaddimah, (t.t, Dar al-Fikri, t.th).

${ }^{7}$ Rozalinda, Ekonomi Islam Teori dan Aplikasinya Pada Aktivitas Ekonomi, (PT. Raja Grafindo Persada: Jakarta, 2014), h. 176.
} 
Artinya: Dan hendaklah ada di antara kamu segolongan umat yang menyeru kepada kebajikan, menyuruh kepada yang ma'ruf dan mencegah dari yang munkar ${ }^{8}$ dan merekalah orang-orang yang beruntung.

Sesuai dengan definisi hisbah di atas maka amar ma'ruf nahi munkar merupakan tugas utama dari institusi hisbah. Al-hisbah adalah institusi keagamaan yang sangat penting dalam lintasan sejarah Ekonomi Islam. Pada dasarnya al-hisbah ini sudah ada pada masa Nabi Saw. Rasulullah sebagai kepala Negara yang berperan sebagai kepala muhtasib pertama dalam Islam. Rasulullah SAW secara langsung melakukan inspeksi ke pasar-pasar untuk mengecek harga dan mekanisme pasar. Rasulullah SAW ketika masih hidup beliau langsung menanggani segala sesuatu yang berkaitan dengan al-amr bi al alma'ruf wa nahy'an al munkar, seperti kasus Zubair ibn Awwan yang enggan memberikan minum kepada laki laki Anshar pada waktu musim kemarau. Kemudian, Rasul menegurnya dan memerintahkan agar Zubair memberikan air minum kepada laki laki tersebut ${ }^{9}$.

Dalam riwayat lain diceritakan bahwa Rasulullah berjalan kepasar-pasar dan enghampiri penjual makanan dan measukkan tangannya kedalam tumpikan makanan tersebut. Beliau terkejut saat endapati tangannya basah. Saat itu Nabi secara langsung menegur pedagang tersebut dan berkata; "mengapa engkau tidak meletakkan makanan yang basah di atas sehingga orang dapat melihatnya, tidak termasuk kepada golonganku siapa yang elakukan penipuan",10. Peristiwa ini enunjukkan bahwa lembaga al-hisbah telah ada pada masa Rasulullah SAW dalam pelaksanaan pengawasan pasar.

Al-Hisbah merupakan pelaksanaan dari amru bi al-ma'ruf wa nahyu'an al munkar $^{11}$ dan mendamaikan manusia yang berselisih. Lembaga ini juga bertugas mengawasi takaran dan timbangan, mengawasi pasar dari kecurangan dan tipuan. Dengan demikian lembaga ini bertugas memberikan pertolongan kepada orang yang tidak mampu menuntut haknya dan menyelesaikan perselisihan yang terjadi diantara manusia serta mengajak kepada kebaikan.

Untuk mengembangkan perdagangan dan industri lembaga al-hisbah memiliki peran yang sangat penting. Tugas al-hisbah ada dua macam: Pertama, tugas utamanya adalah melakukan pengawasan umum yang berkaitan dengan pelaksanaan kebajikan. Kedua, khusus berkaitan dengan kegiatan pasar, pengawasan secara umum. Pengawas dilakukan atas berbagai hal seperti perindustrian dan perdagangan berkaitan dengan administratif dan pemeliharaan kualitas dan standar produk. Al-hisbah secara rutin melakukan pengecekan atas ukuran, takaran dan tibangan, kualitas barang, menjaga jual beli yang jujur dan menjaga agar selalu stabil. ${ }^{12}$

Dalam perjalanan sejarah institusi al-hisbah terus mengalami perubahan dan modifikasi sesuai dengan perkembangan yang terjadi dalam masyarakat. Pada mulanya,

\footnotetext{
${ }^{8}$ Ma'ruf: segala perbuatan yang mendekatkan kita kepada Allah; sedangkan Munkar ialah segala perbuatan yang menjauhkan kita dari pada-Nya.

${ }^{9}$ Rozalinda, Ekonomi Islam Teori dan Aplikasinya Pada Aktivitas Ekonomi, (PT. Raja Grafindo Persada: Jakarta, 2014), h. 178.

${ }^{10}$ Muslim Ibnu al-Hajjaj Abu al-Husain al-Khusairi Al-Naisaburi, Shahih Muslim, (Beirut: Dar Ihya alTurats al-Arabi, t.t),hal.69.

${ }^{11}$ Taqiyuddin Ibnu Taiiyah, al-Hisbah fi al-Islam, (Riyadh: Mansyurat al-Muassasah al-Sa'idiyah, t.t), hal.46.

${ }^{12}$ Rozalinda, Ekonomi Islam Teori dan Aplikasinya Pada Aktivitas Ekonomi, (PT. Raja Grafindo Persada: Jakarta, 2014), h. 179.
} 
lembaga ini merupakan institusi keagamaan yang mempunyai tugas yang sangat umum yakni melakukan amar ma'ruf nahy munkar. Muhtasib mempunyai wewenang memerintahkan orang untuk melaksanakan shalat jum'at melarang orang memukul anaknya dengan keras, menjaga kebersihan dijalan dan di pasar, melarang minum minuman keras, berzina, dan lain-lain. Ini berarti tugas al-hisbah menyangkut masalah moral dan keagamaan masyarakat. Baru pada abad ke-8 institusi ini hanya bertugas mengawasi masalah sosial ekonomi.

Istitusi al-hisbah pada dasarnya mempunyai beberapa fungsi, sebagai berikut :

1. Fungsi ekonomi

Al-hisbah adalah sebuah institusi ekonomi yang berfungsi melakukan pengawasan terhadap kegiatan ekonomi dipasar, seperti pengawasan harga, takaran dan timbangan, praktik jual beli terlarang dan lain-lain. Institusi ini juga berfungsi meningkatkan produktivitas dan pendapatan. Secara khusus ada beberapa fungsi ekonomi:

a. Memastikan tercukupinya kebutuhan bahan pokok, muhtasib harus selalu mengecek ketersediaan barang-barang kebutuhan pokok.

b. Pengawasan terhadap industri, tugas utama muhtasib adalah mengawasi standarisasi produk.

c. Pengawas terhadap jasa, muhtasib mempunyai wewenang untuk mengecek apakah seorang dokter, ahli bedah, dan sebagainya telah melaksanakan tugasnya secara baik atau belum. ${ }^{13}$

d. Pengawasan atas perdagangan, muhtasib harus mengawasi pasar secara umum, mengawasi takaran, timbangan dan ukuran, serta kualitas produk.

Muhtasib juga berwenang mengawasi barang barang yang masuk ke pasar dan bongkar muat di pasar, dalam mengawasi aktivitas pasar muhtasib terdiri dari:

a. Pengawasan harga, ukuran, takaran dan timbangan.

b. Mengawasi jual beli terlarang.

c. Pengawasan praktik riba, maysir dan gharar.

d. Mengawasi standar kemahalan, kesehatan, dan kebersihan suatu komoditas.

e. Pengaturan pasar.

f. Mengatasi persengketaan dan ketidakadilan antara sesama pedagang dan antara pedagang dengan pembeli baik menyangk ututang-piutang, maupun harga.

g. Melakukan intervensi pasar.

h. Melakukan intervensi pasar dan harga.

\section{Fungsi Sosial}

Fungsi sosial institusi al-hisbah adalah mewujudkan keadilan sosial dan keadian distributif dalam masyarakat. Lewat tugasnya memberikan informasi kepada para pedagang dan konsumen, memberikan kesempatan yang sama kepada setiap orang dan menghilangkan penguasaan sepihak terhadap jalur produksi dan distribusi di pasar.

\footnotetext{
${ }^{13}$ Abdul Azhim Islahi, Consepts of Ibnu Tayiyah, (London: The Islamic Foundation, 1824), hal.187.
} 


\section{Fungsi Moral}

Institusi al-hisbah adalah lembaga pengawas berlangsungnya moral dan akhlak Islami dalam berbagai interaksi dan prilaku konsumen dan produsen di pasar. Tugasnya adalah mewujudkan perekonomian yang bermoral yang berlandaskan pada Al-Qur'an dan sunnah. Muhtasib boleh menjatuhkan hukuman terhadap berbagai pelanggaran kejahatan yang terjadi di pasar. Hukumnya dijatuhkan adalah hukuman $t^{\prime}{ }^{\prime} z i r^{14}$.

Dalam pelaksanaan hukuman muhtasib harus memperhatikan sesuainya hukuman tersebut dengan maqashid syar'iah. Muhtasib harus mempertimbangkan bahwa dengan hukuman tersebut pelaku pelanggaran bisa jera dan tidak mengulanginya lagi. Oleh sebab itu, muhtasib bebas meilih hukuman yang akan dijatuhkan terhadap pelaku pelanggaran mulai dari hukuman yang paling ringan sapai hukuman yang paling berat, mulai dari peberian peringatan, ajakan, ancaman, celaan, pukulan dan hukuan penjara. ${ }^{15}$

\section{Analisis Terhadap Peran Peerintah Dalam Mengawasi Pasar}

Pelaksanaan tugas pemerintah dalam mengawasi jalannya aktivitas pasar memegang peranan yang sangat penting untuk terciptanya tertip pasar, tertib harga, tertib takaran dan tibangan serta tata kelola pasar sehingga menjadikan pasar sebagai tempat yang benar-benar ideal dan nyaman untuk melakukan kegiatan jual beli. Kondisi ini merupakan kondisi yang sangat didambakan oleh semua pihak. Masyarakat selaku konsumen menginginkan adanya keadilan dalam transaksi jual beli, pemerintah selaku pelaksana tugas pengawasan terhadap pasar menginginkan adanya kepatuhan pedagang dalam melaksanakan ketentuan dan peraturan yang berkaitan dengan takaran dan timbangan, tata kelola pasar dan lain-lain. Sehingga tugas pemerintah dalam melakukan pengawasan terhadap pasar dapat dicapai.

Pengawasan pemerintah terhadap pasar dalam hal ketepatan takaran dan tibangan yang dilaksanakan melalui Direktorat Metrologi atau Balai Metrologi Perdagangan berperan penting untuk memberikan pelayanan dalam bidang kemetrologian kepada masyarakat luas sehingga akan tercipta tertib ukur. Apabila diperhatikan, dilihat dan dicerati, tugas Balai Metrologi legal sebagai lebaga yang ditugaskan Negara yaitu Menteri Perindustrian dan Perdagangan untuk elakukan tugas sebagai berikut:

1) Mengelola standar ukuran dalam bentuk pemeriksan alat-alat Ukur, Takaran, Timbangan dan Peralatannya (UTTP).

2) Pengawasan dan penyuluhan kemetrologian.

3) Pengawasan terhadap Barang Dalam Kemasan (BDKT), mempunyai tugas dan wewenang yang hapir sama dengan al-hisbah yang ada dalam Islam dengan tugas utama adalah amar ma'ruf dan nahi unkar, mengawasi pasar, mencegah terjadinya kecurangan serta mengawasi takaran dan tibangan.

Tugas dan wewenang Badan Metrologi Legal perspektif ekonomi Islam dapat dilihat dari beberapa aspek: Pertama, dari segi pengelolaan terhadap standar ukur. Metrologi legal sebagai lebaga pemerintah yang memiliki kesamaan tugas dengan al-hisbah yang ada dalam konsep Islam, yaitu elakukan pengawasan terhadap takaran dan timbangan.

\footnotetext{
${ }^{14}$ Hukuan Ta'zir adalah huku yang tidak ditentukan jenis, kadar dan julah oleh syara, tetapi diserahkan sepenuhnya kepada hakim untuk enetapkan hukuan yang sesuai bagi pelaku pelanggaran.

${ }^{15}$ Taqiyuddin Ibnu Taiiyah, al-Hisbah fi al-Islam,.......hal, 89.
} 
Kedua, Dari segi pengawasan dan penyuluhan kemetrologian, tugas pengawasan dan penyuluhan kemetrologian merupakan tugas yang dilakukan dalam upaya mencegah terjadinya tindakan penyelewengan peakaian alat ukur takar dan tibangan yang dipakai oleh pedagang yang membawa kecurangan dan penipuan dalam takaran dan tibangan. Hal ini sejalan dengan tugas yang dijalankan oleh lembaga al-hisbah pada zaman Rasulullah SAW, yaitu melakukan pengawasan terhadap pasar, mencegah terjadinya kecurangan dalam takaran dan tibangan, penibunan barang dan amar ma'ruf dan nahi munkar.

\section{Kesimpulan}

Kegiatan Perdagangan memiliki peran yang sangat penting dalam kehidupan manusia. Sektor perdagangan dianggap cukup menjanjikan dalam meningkatkan kesejahteraan kehidupan manusia. Pasar adalah salah satu tempat setrategis untuk bertemunya penjual dan pembeli guna melakukan transaksi jual beli. Pasar dan perdagangan yang terjadi didalamnya yang tujun dasarnya adalah untuk mencari keuntungan dengan cara dan aturan main yang telah ditetapkan, sewaktu-waktu dapat diselewengkan oleh oknum pelaku ekonomi dengan tujuan mendapatkan keuntungan lebih.

Islam telah memberikan aturan tentang masalah takaran dan timbangan. Dalam Alquran disebutkan secara tegas perintah untuk menyempurnakan takaran dan timbangan secara benar, perintah ini juga dibarengi dengan ancaman bagi orang yang melakukan kecurangan. Terdapat perintah yang menyatakan bahwa setiap muslim harus menyempurnakan takaran dan timbangan secara adil dan sempurna.

Dalam ekonomi Islam, urusan takaran dan timbangan bukan hanya menjadi urusan individu seseorang atau lebih, akan tetapi menjadi urusan negara. Pemerintah mempunyai tugas dan wewenang dalam mengatur dan mengawasi pasar yang salah satunya urusan takaran dan timbangan sebagai bentuk antisipasi terjadinya kecurangan. Lembaga yang bertugas dalam pengawasan ini adalah lembaga al-hisbah.

Dewasa ini Pemerintah melalui Direktorat Metrologi atau Balai Metrologi Departemen Perdagangan mempunyai tugas dan wewenang memberikan pelayanan dan penyuluhan dalam bidang kemetrologian kepada asyarakat sehingga akan tercipta tertib ukur, takar dan tibangan dalam teransaksi perdagangan. Dilihat dari segi pengelolaan terhadap standar ukur, Badan Metrologi Legal sebagai perpanjangan tangan dari pemerintah memiliki tugas dan wewenang yang sama dengan al-hisbah yang ada dalam konsep ekonomi Islam, yaitu mengawasi takaran dan timbangan. Dilihat dari segi penyuluhan kemetrologian yang dilakukan oleh Balai Metrologi terdapat perbedaan dengan al-hisbah yang ada dizaman Rasulullah SAW.

Tugas al-hisbah dalam menegakkan amar ma'ruf dan nahi munkar menyentuh sampai kepada moral dan perilaku baik para pelaku pasar yang terdiri dari masyarakat, penjual dan pembeli. Al-hisbah berkewajiban mencegah terjadinya penipuan dan kecurangan yang dapat merugikan konsumen dari segi kualitas barang maupun cara dan perilaku para pedagang dalam menakar dan menimbang barang dagangan. Sedangkan Balai Metrologi hanya menyentuh keabsahan dan kebenaran alat ukur, takar dan tibangan yang dipakai para pedagang, tidak merambah pada perilaku dan cara pedagang dalam menggunakan alat-alat tersebut. Semestiya pemerintah juga mengambil peran sampai kepada ranah moral para pedagang, bukan hanya sebatas keabsahan alat ukur, namun juga menyentuh masalah moral para pedadang. Pengawasan pemerintah terhadap kualitas 
barang, cara menimbang, tata kelola pasar yang dipertegas dengan pemberian hukuman kepada pedagang yang melakukan kecurangan dan tidak mematuhi ketentuan yang telah ditetapkan.

\section{Daftar Pustaka}

Abdul Azim Islahi. Ekonomi Consepts Of Ibnu Taimiyah. London : The Islamic Foundation, 1824.

Abdul Aziz Dahlan. Ensiklopedi Isla. Jakarta: PT. Ichtiar Van Hoeke. 1984.

Abdurrahman Ibnu Khaldun.Muqaddimah, t.t, Dar al-Fikri, t.th.

Muslim Ibnu al-Hajjaj Abu al-Husain al-Khusairi Al-Naisaburi. Shahih Muslim. Beirut: Dar Ihya al-Turats al-Arabi, t.t.

Rozalinda, Ekonomi Islam Teori dan Aplikasinya Pada Aktivitas Ekonomi. PT. Raja Grafindo Persada: Jakarta, 2014.

Taqiyuddin Ibnu Taiiyah. al-Hisbah fi al-Islam. Riyadh: Mansyurat al-Muassasah alSa'idiyah, t.t 